\title{
Oral colonization by Candida species and associated factors in HIV-infected patients in Ahvaz, southwest Iran
}

\author{
Elham Aboualigalehdari', Maryam Tahmasebi Birgani ${ }^{2}$, Mahnaz Fatahinia ${ }^{1,3}$, Mehran Hosseinzadeh ${ }^{4}$ \\ 'Department of Medical Mycology, School of Medicine, Ahvaz Jundishapur University of Medical Sciences, Ahvaz, Iran; ${ }^{2}$ Department of Medical \\ Genetics, School of Medicine, Ahvaz Jundishapur University of Medical Sciences, Ahvaz, Iran; ${ }^{3}$ Infectious and Tropical Diseases Research \\ Center, Health Research Institute, School of Medicine, Ahvaz Jundishapur University of Medical Sciences, Ahvaz, Iran; ${ }^{4}$ Thalassemia and \\ Hemoglobinopathy Research Center, Health Research Institute, Ahvaz Jundishapur University of Medical Sciences, Ahvaz, Iran
}

\begin{abstract}
OBJECTIVES: Oropharyngeal candidiasis is one of the most common opportunistic fungal infections among human immunodeficiency virus (HIV)-infected individuals. The most common cause is Candida albicans, followed by non-albicans Candida. This study aimed to identify colonized Candida species in HIV-infected patients from Ahvaz, Iran. Additionally, the relationships between immunity-related factors, lifestyle, and colonization of Candida spp. were studied.

METHODS: Oral swabs were taken from 201 HIV-positive patients referred for consultations at the Behavioral Modification Center. Oral Candida colonization was detected using culture-based and molecular assays. Data were assessed by descriptive statistics and analyzed to investigate the correlation between Candida colonization and various factors, including the $\mathrm{CD} 4^{+}$cell count and viral load.

RESULTS: It was found that $43.8 \%$ of patients were positive for Candida. The most common species was C. albicans (48.0\%), followed by non-albicans Candida isolates, including C. dubliniensis, C. glabrata, C. tropicalis, C. parapsilosis, C. guilliermondii, C. kefyr, and C. krusei. Colonization of Candida spp. in patients was associated with a CD4 count $\leq 200 \mathrm{cells} / \mathrm{mm}^{3}$ (odds ratio [OR], 4.62; $\mathrm{p}<0.05)$, history of shared injections (OR, 6.96; $\mathrm{p}<0.001)$, and $\operatorname{sex}(\mathrm{OR}, 3.59 ; \mathrm{p}<0.05)$.

CONCLUSIONS: The results of this study showed that C. albicans was the dominant pathogen. The risk factors for colonization of Candida spp. were a CD4 count $\leq 200 / \mathrm{mm}^{3}$, a history of shared injections, and sex. Other factors with potential relationships include viral load, age, and opportunistic infections, but further investigations are needed.
\end{abstract}

KEY WORDS: Candidiasis, Oral, Species, Colonization, Human immunodeficiency virus, Iran

\section{INTRODUCTION}

Oropharyngeal candidiasis (OPC) is an opportunistic fungal infection that affects the oral mucosa. Although Candida albicans is the most common causative agent of OPC, non-albicans Candida species have also been reported to be responsible for OPC,

\section{Correspondence: Mahnaz Fatahinia}

Department of Medical Mycology, School of Medicine, Ahvaz Jundishapur University of Medical Sciences, Ahvaz 61357-15794, Iran E-mail: fatahinia@yahoo.com

Received: Mar 10, 2020 / Accepted: May 24, 2020 / Published: May 24, 2020

This article is available from: https://e-epih.org/

(c) This is an open-access article distributed under the terms of the Creative Commons Attribution License (https://creativecommons.org/licenses/by/4.0/), which permits unrestricted use, distribution, and reproduction in any medium, provided the original work is properly cited.

(C) 2020, Korean Society of Epidemiology which is mostly observed in patients undergoing chemotherapy and in transplant recipients. OPC is also one of the most frequent infections in human immunodeficiency virus (HIV)-infected patients, as it has been observed in more than $90 \%$ of HIV patients. Remarkably, OPC has been detected in early stages of HIV before treatment, as well as in advanced stages of acquired immune deficiency syndrome (AIDS) [1,2].

OPC is mostly diagnosed through its clinical manifestations, which include a burning sensation, buccal pain, taste changes, and pseudomembranous, erythematous, and angular cheilitis $[3,4]$. To treat $\mathrm{OPC}$, it is necessary to identify the causative species because a majority of infections contain mixed Candida spp. Both C. albicans and non-albicans Candida spp. may be affected by acquired and intrinsic antifungal resistance, which could influence the management of the disease and contribute to the spread of candidiasis to esophageal tissue, malnutrition, and interference 
with drug absorption. Consequently, the identification of the causative species is necessary and the diagnosis should be made using both culture and molecular methods [5-7]. Oral candidiasis is a prognostic indicator in HIV patients, as well as a predisposing factor for fungal infections such as candidemia and esophageal candidiasis. Dental prostheses, smoking, and hormonal, nutritional, immunological, and salivary changes predispose HIV patients to oral candidiasis $[3,8,9]$.

The current study aimed to evaluate the colonization of Candida spp. in HIV-positive patients, to determine the distribution of Candida spp., and to identify the relationships of Candida spp. colonization with a CD4 count $\leq 200$ cells $/ \mathrm{mm}^{3}$, viral load, history of shared injections, sex, age, intravenous drug use, underlying disease (hepatitis C, tuberculosis [TB], hepatitis B, Pneumocystis carinii pneumonia $[\mathrm{PCP}]$ ), having a safe and secure sexual relationship, the use of antiretroviral medication, and the use of prophylactic medication (for PCP and TB).

\section{MATERIALS AND METHODS}

\section{Study subjects}

HIV-infected outpatients aged 6-81 years $(n=201)$ were referred for consultations to the Behavioral Disease Center of Ahvaz Jundishapur University of Medical Sciences, Ahvaz, Iran from December 2018 to April 2019 for viral load and CD4 ${ }^{+}$T-cell count measurements. HIV positivity was the sole inclusion and exclusion criterion for sampling.

The subjects were interviewed about their medical history and information was extracted from their medical records on sex, age, intravenous drug use, underlying diseases (hepatitis $C, T B$, hepatitis B, and PCP), whether they had a safe and secure sexual relationship, antiretroviral medication use, and history of using prophylaxis drugs (for PCP and TB).

\section{Initial identification of yeasts}

Samples from the oral cavity of HIV-positive participants were collected with a sterile cotton swab, seeded onto CHROMagar Candida plates (CHROMagar, Pioneer, Paris, France), and incubated aerobically at $37^{\circ} \mathrm{C}$ for $48-72$ hours. Colonies with similar morphology and color on CHROMagar plates were counted and the result was expressed in colony-forming units per milliliter (CFU/mL) after $48-72$ hours of incubation at $37^{\circ} \mathrm{C}$ on $\mathrm{CHRO}-$ Magar plates. Patients with $\geq 10 \mathrm{CFU} / \mathrm{mL}$ were considered to be colonized [10].

Patients who were asymptomatic for oral candidiasis with $\geq 10$ $\mathrm{CFU} / \mathrm{mL}$ were defined as having been colonized by Candida, but asymptomatic patients with $<10 \mathrm{CFU} / \mathrm{mL}$ were considered noncolonized. The next step was the purification of isolates, which were cultured on Sabouraud Dextrose agar (Lifoilchem, Roseto degli Abruzzi, Italy). The initial identification of isolates to the species level was performed by classical and standard methods such as germ tube test, growth at $45^{\circ} \mathrm{C}$, and production of chlamydoconidia and hyphae on corn meal agar (Lifoilchem) with Tween 80 .
Table 1. List of primers used in this study

\begin{tabular}{lc}
\hline Primers & Reference \\
\hline ITS1 5'-TCC-GTA-GGT-GAA-CCTGCG-G-3' & {$[9]$} \\
ITS4 5'-TCC-TCC-GCT-TAT-TGA-TAT-GC-3' & \\
CALF 5'-TGGTAAGGCGGGATCGCTT-3' & {$[13]$} \\
CALR 5'-GGTCAAAGTTTGAAGATATAC-3' & \\
CDUF 5'-AA ACTTGTCACGAGATTATTTTT-3' & {$[13]$} \\
CDUR 5'-AAA GTTTGAAGAATAAAATGGC-3 & \\
\hline
\end{tabular}

\section{Molecular identification of yeasts}

Firstly, the genomic DNA was directly extracted from purified colonies in sterile distilled water by boiling $[6,11]$. Polymerase chain reaction (PCR) was performed by sequencing an internal transcribed spacer (ITS1-5.8S rDNA-ITS2) region and using universal fungal primers (Table 1 ). The PCR amplification conditions consisted of an initial denaturation at $95^{\circ} \mathrm{C}$ for 5 minutes, followed by 35 cycles at $95^{\circ} \mathrm{C}$ for 35 seconds, $58^{\circ} \mathrm{C}$ for 30 seconds, $72^{\circ} \mathrm{C}$ for 1 minute, and a final extension at $72^{\circ} \mathrm{C}$ for 10 minutes. All PCR tests had a negative (no template) control and a positive (sequence template) control. Finally, to determine the species, the positive specimens were identified by restriction fragment length polymorphisms [12]. Each of the amplified PCR products was digested using MspI (Hpa III; Thermo Fisher Scientific, Waltham, MA, USA) restriction enzymes and incubated at $37^{\circ} \mathrm{C}$ for $1-16$ hours. The digested products were run on $2 \%$ agarose gel and stained with $0.5 \mu \mathrm{g} / \mathrm{mL}$ ethidium bromide. Since the MspI enzyme is not able to differentiate C. albicans from C. dubliniensis or C. albicans from C. dubliniensis, isolates suspected to be C. albicans or C. dubliniensis were distinguished by duplex PCR using primers targeting sequences in the ITS- 1 and ITS- 2 regions of the rDNA (Table 1) [13]. The PCR reaction started at $95^{\circ} \mathrm{C}$ for 5 minutes, followed by 35 cycles of $95^{\circ} \mathrm{C}$ for 30 seconds, $60^{\circ} \mathrm{C}$ for 45 seconds, $72^{\circ} \mathrm{C}$ for 30 seconds, and a final extension at $72^{\circ} \mathrm{C}$ for 5 minutes.

\section{Statistical analysis}

Data were assessed using descriptive statistics (frequency, percentage, mean, standard deviation). Associations between categorical variables were analyzed using the chi-square test or Fisher exact test. Variables with $\mathrm{p}$-value $<0.2$ in the univariate analysis were included in the multiple logistic regression analysis model. Multicollinearity was checked, and all variables had a variance inflation factor well below 5 . The Hosmer-Lemeshow test was used to evaluate the goodness-of-fit for multiple logistic regression. The Kolmogorov-Smirnov test was used to assess the normality of the distribution of continuous variables, and variables that did not have a normal distribution were compared using the MannWhitney test. All analyses were performed using $\mathrm{R}$ version 3.5.2 (https://cran.r-project.org/bin/windows/base/old/3.5.2/) and SPSS version 22 (IBM Corp., Armonk, NY, USA). A p-value $<0.05$ was set as the threshold for statistical significance. 
Table 2. The frequency of socio-demographic characteristics of the study subjects

\begin{tabular}{|c|c|c|c|}
\hline Variables & Colonized $(n=88)$ & Non-colonized $(n=113)$ & $p$-value ${ }^{1}$ \\
\hline \multicolumn{4}{|l|}{ Sex } \\
\hline Male & $63(54.8)$ & $52(45.2)$ & $<0.001$ \\
\hline Female & $25(29.1)$ & $61(70.9)$ & \\
\hline \multicolumn{4}{|l|}{ Drug injection } \\
\hline True & $47(57.3)$ & $35(42.7)$ & 0.001 \\
\hline False & $41(34.5)$ & $78(65.5)$ & \\
\hline \multicolumn{4}{|l|}{$\mathrm{TB}$} \\
\hline Yes & $15(68.2)$ & $7(31.8)$ & 0.015 \\
\hline No & $73(40.8)$ & $106(59.2)$ & \\
\hline \multicolumn{4}{|l|}{ TB prophylaxis } \\
\hline Yes & $6(30.0)$ & $14(70.0)$ & 0.191 \\
\hline No & $82(45.3)$ & $99(54.7)$ & \\
\hline \multicolumn{4}{|l|}{ PCP } \\
\hline Positive & $12(63.2)$ & $7(36.8)$ & 0.074 \\
\hline Negative & $76(41.8)$ & $106(58.2)$ & \\
\hline \multicolumn{4}{|l|}{ ARV } \\
\hline Yes & $85(42.9)$ & $113(57.1)$ & 0.082 \\
\hline No & $3(100)$ & $0(0.0)$ & \\
\hline \multicolumn{4}{|l|}{ Blood transfusion } \\
\hline True & $1(100)$ & $0(0.0)$ & 0.438 \\
\hline False & $87(43.5)$ & $113(56.5)$ & \\
\hline \multicolumn{4}{|c|}{ Mother-to-child transmission } \\
\hline True & $3(60.0)$ & $2(40.0)$ & 0.655 \\
\hline False & $85(43.4)$ & $111(56.6)$ & \\
\hline \multicolumn{4}{|l|}{ Addiction history } \\
\hline Yes & $51(49.5)$ & $52(50.5)$ & 0.093 \\
\hline No & $37(37.8)$ & $61(62.2)$ & \\
\hline \multicolumn{4}{|l|}{ Education } \\
\hline No education & $11(57.9)$ & $8(42.1)$ & $0.193^{2}$ \\
\hline Elementary education & $75(41.7)$ & $105(58.2)$ & \\
\hline Higher education & $2(100)$ & $0(0.0)$ & \\
\hline \multicolumn{4}{|l|}{ Homosexuality } \\
\hline True & $5(71.4)$ & $2(28.6)$ & 0.244 \\
\hline False & $83(42.8)$ & $111(57.2)$ & \\
\hline \multicolumn{4}{|l|}{ HCV Ag } \\
\hline Positive & $31(50.0)$ & $31(50.0)$ & 0.235 \\
\hline Negative & $57(41.0)$ & $82(59.0)$ & \\
\hline \multicolumn{4}{|l|}{ HBV Ag } \\
\hline Positive & $4(50.0)$ & $4(50.0)$ & 0.732 \\
\hline Negative & $84(43.5)$ & $109(56.5)$ & \\
\hline \multicolumn{4}{|l|}{ Occupational exposure } \\
\hline True & $1(50.0)$ & $1(50.0)$ & 1.000 \\
\hline False & $87(43.7)$ & $112(56.3)$ & \\
\hline \multicolumn{4}{|l|}{ Shared injection history } \\
\hline Yes & $37(72.5)$ & $14(27.5)$ & $<0.001$ \\
\hline No & $51(34.0)$ & $99(66.0)$ & \\
\hline \multicolumn{4}{|l|}{ CD4 count (cells/mm³) } \\
\hline$\leq 200$ & $20(80.0)$ & $5(20.0)$ & $<0.001$ \\
\hline$>200$ & $68(38.6)$ & $108(61.4)$ & \\
\hline
\end{tabular}

Values are presented as number (\%).

TB, tuberculosis; PCP, Pneumocystis carinii pneumonia; ARV, antiretroviral; HCV, hepatitis C virus; HBV, hepatitis B virus; Ag, antigen.

${ }^{1} \mathrm{Chi}$-square test or Fisher exact test.

${ }^{2}$ Tests were performed after pooling the last 2 groups (elementary education, higher education) in order to eliminate small expected frequencies. 
Table 3. Characteristics of the study population

\begin{tabular}{|c|c|c|c|c|c|}
\hline \multirow{2}{*}{ Variables } & \multicolumn{2}{|r|}{ Colonized } & \multicolumn{2}{|r|}{ Non-colonized } & \multirow{2}{*}{$\mathrm{p}$-value } \\
\hline & $n$ & Mean \pm SD & $\mathrm{n}$ & Mean \pm SD & \\
\hline Age & 88 & $40.61 \pm 12.55$ & 113 & $37.15 \pm 8.18$ & 0.005 \\
\hline Viral load & 36 & $802,637.71 \pm 2,544,107.27$ & 27 & $3,150,032.340 \pm 11,343,051.38$ & 0.064 \\
\hline Candida load & 88 & $5,787.51 \pm 23,256.64$ & 58 & $3.50 \pm 2.12$ & $<0.001$ \\
\hline
\end{tabular}

SD, standard deviation.

'Mann-Whitney test.

Table 4. Prevalence rates of oral colonization by Candida species

\begin{tabular}{lcc}
\hline Variables & OR $(95 \% \mathrm{Cl})$ & $\mathrm{p}$-value \\
\hline Sex (ref: female) & $3.59(1.23,10.46)$ & 0.019 \\
Age & $1.01(0.98,1.04)$ & 0.376 \\
Drug injection (ref: false) & $0.78(0.22,2.68)$ & 0.697 \\
TB (ref: no) & $1.75(0.55,5.57)$ & 0.341 \\
TB prophylaxis (ref: no) & $0.65(0.21,2.03)$ & 0.466 \\
PCP (ref: negative) & $1.10(0.31,3.89)$ & 0.872 \\
Addiction history (ref: no) & $0.28(0.07,1.03)$ & 0.056 \\
Education (ref: yes) & $1.98(0.64,6.17)$ & 0.234 \\
Shared injection history (ref: no) & $6.96(2.46,19.65)$ & $<0.001$ \\
CD4 (ref: $>$ 200) & $4.62(1.43,14.90)$ & 0.010 \\
\multicolumn{2}{c}{ Hosmer-Lemeshow test ${ }^{1}: \chi^{2}=8.49, p=0.387$} \\
\end{tabular}

$\mathrm{OR}$, odds ratio; $\mathrm{Cl}$, confidence interval; $\mathrm{TB}$, tuberculosis; $\mathrm{PCP}$, Pneumocystis carinii pneumonia; ref, reference.

${ }^{1}$ The Hosmer-Lemeshow test is a statistical test for goodness-of-fit for logistic regression models. It is used frequently in risk prediction models.

\section{Ethics statement}

This cross-sectional study received ethical approval from the research deputy of Jundishapur University of Medical Sciences, Ahvaz, Iran (code\#1397/893).

\section{RESULTS}

The current study analyzed 201 HIV-infected patients, including 115 male and 86 female patients aged 6-81 years. Patients' sociodemographic characteristics are summarized in Table 2 . The colonized $(\geq 10 \mathrm{CFU} / \mathrm{mL})$ and non-colonized groups $(<10 \mathrm{CFU} / \mathrm{mL})$ accounted for $43.8 \%$ and $56.2 \%$ of the sample, respectively. No statistically significant differences were found between the 2 groups in terms of TB prophylaxis, PCP, antiretroviral therapy, blood transfusion, mother-to-child transmission, addiction history, homosexuality, education, occupational exposure, and hepatitis B or hepatitis $\mathrm{C}$ virus infection, although people with male sex, a history of drug injection, $\mathrm{TB}$, a history of shared injections, and a CD4 count $\leq 200 / \mathrm{mm}^{3}$ were more likely to be colonized $(\mathrm{p}<0.05)$.

The age distribution and Candida load in the colonized group were significantly different from those of the non-colonized group, although the viral load was similar in the 2 groups (Table 3 ). The p-value of the Hosmer-Lemeshow test was 0.387, indicating a goodness-of-fit data. The factors associated with colonization were
Table 5. Distribution of Candida strains ( $n=127)$ isolated from colonized patients $(n=88)$

\begin{tabular}{lcc}
\hline Species & $\begin{array}{c}\text { Isolation rate by } \\
\text { species, } \mathrm{n}(\%)\end{array}$ & $\begin{array}{c}\text { Isolation rate by } \\
\text { patients, \% }\end{array}$ \\
\hline Candida albicans & $61(48.0)$ & 69.3 \\
Candida dubliniensis & $29(22.8)$ & 32.9 \\
Candida glabrata & $18(14.1)$ & 20.4 \\
Candida tropicalis & $8(6.2)$ & 9.1 \\
Candida parapsilosis & $5(3.9)$ & 5.6 \\
Candida guilliermondii & $3(2.3)$ & 3.4 \\
Candida kefyr & $3(2.3)$ & 3.4 \\
Candida krusei & $1(0.7)$ & 1.1 \\
\hline
\end{tabular}

Table 6. Distribution of co-colonization with different yeast species in 88 colonized patients

\begin{tabular}{lc}
\hline Mixed colonization of species & Patients, $\mathrm{n}(\%)$ \\
\hline C. albicans+C. dubliniensis & $6(6.8)$ \\
C. albicans+C. glabrata & $5(5.6)$ \\
C. albicans+C. dublinensis+C. glabrata & $4(4.5)$ \\
C. dubiliansis+C. glabrata & $4(4.5)$ \\
C. albicans+C. tropicalis & $2(2.2)$ \\
C. albicans+C. guilliermondii & $2(2.2)$ \\
C. albicans+C. dubilinensis+C. kefyr & $1(1.1)$ \\
C. albicans+C. glabrata+C. tropicalis & $1(1.1)$ \\
C. dubiliansis+C. parapsilosis & $1(1.1)$ \\
C. dubilinensis+C. tropicalis & $1(1.1)$ \\
C. glabrata+C. tropicalis & $1(1.1)$ \\
C. dubilinensis+C. kefyr & $1(1.1)$ \\
\hline
\end{tabular}

subjected to multiple logistic regression analysis. Sex (odds ratio [OR], 3.59; 95\% confidence interval [CI], 1.23 to 10.46; $\mathrm{p}<0.05$ ), a history of shared injections (OR, 6.96; 95\% CI, 2.46 to 19.65; $\mathrm{p}<$ 0.001), and CD4 count (OR, 4.62; 95\% CI, 1.43 to $14.90 ; \mathrm{p}<0.05$ ) showed significant differences between the colonized and noncolonized groups (Table 4).

From the study population, 127 strains of Candida were isolated in 88 colonized patients. C. albicans was the most common strain isolated, accounting for $48.0 \%$ of isolates (61/127), while non-albicans Candida strains were found in the remaining 52.0\% of isolates (66/127). The most common species among the nonalbicans Candida isolates were $C$. dubliniensis and C. glabrata, with 
prevalence rates of $22.8 \%(n=29)$ and $14.1 \%(n=18)$, respectively. The distribution of the isolated species is shown in Table 5 .

In 32 patients (36.4\%), more than 1 Candida spp. was isolated. The cocolonization distribution is shown in Table 6.

\section{DISCUSSION}

The aim of this study was to obtain epidemiological data on the colonization of different Candida species in HIV-infected patients in Ahvaz, Iran. HIV patients have a high incidence of Candida colonization and are more susceptible to OPC [14,15].

In our study, the rate of Candida colonization in patients with HIV infection was $43.8 \%$, which is similar to those reported in other studies conducted in China (49.5\%), Brazil (50.4\%), and Taiwan $(51.4 \%)[3,16]$. However, a very broad range of Candida colonization rates among HIV-infected patients (11-96\%) has been reported in other studies [10]. The prevalence of Candida spp. colonization may vary based on factors such as sampling methods, diagnostic techniques, and geographical and ethnic differences $[10,17]$. Colonization ranges of $16-56 \%$ have been reported using swab mouth sampling [10].

In a review study by Patil et al. [18] in 2018, the most common strain isolated from HIV patients with OPC was C. albicans (37.295.2\%), followed by C. glabrata (0.99-23.00\%). In our study, C. albicans was the most common oral yeast in $\mathrm{HIV}$-infected patients with a frequency of $69.3 \%$ [19-22]. On one hand, C. dubliniensis has been reported to be the second most common and dominant non-albicans Candida spp. in some studies, followed by C. glabrata [2,22-24]; on the other hand, other studies have identified C. glabrata as the most common non-albicans Candida spp. [19,25, 26]. In recent years, we have witnessed an increase in C. dubliniensis as the most prevalent species after C. albicans even in healthy individuals without HIV $[27,28]$. The absence of molecular techniques in the past when species were identified using traditional methods may explain this phenomenon, because C. dubliniensis is similar to C. albicans and has wrongly been reported as C. albicans.

The increase in C. dubliniensis among HIV patients is concerning because exposure to fluconazole may aggravate fungal adhesion to the oral epithelium. Since HIV-infected patients receive fluconazole to prevent this adhesion [27,29], there is a risk of increasing oropharyngeal candidiasis with C. dubliniensis and other non-albicans Candida spp., as well as resistance to fluconazole, leading to prolonged treatment and higher morbidity and mortality rates due to OPC [5,30-32].

In our study of 88 colonized patients, 59 (67.0\%) had only 1 type of Candida spp. and the remaining patients (32.9\%) had a combination of 2 or 3 yeast species. It can be clinically challenging when susceptible and less susceptible or resistant species to an antifungal medication coexist (i.e., coinfection), such as C. glabrata and C. krusei, which are less susceptible to fluconazole and voriconazole and were present in $14.1 \%$ and $0.7 \%$ of Candida carriers in this study, respectively. In contrast, C. parapsilosis and C. tropicalis (3.9\% and $6.2 \%$ of Candida carriers in this study, respective- ly) have a similar sensitivity to that of C. albicans [18].

These observations underscore the importance of species assessment using Candida CHROMagar medium, which is a lowcost and convenient method of species identification, especially for samples involving more than 1 species [33]. The factors potentially related to oral colonization by Candida spp. in HIV-infected individuals were evaluated in this study. Through multiple logistic regression analysis, one of the risk factors for Candida colonization was identified as a CD4 count $\leq 200 / \mathrm{mm}^{3}$ (OR, 4.62; 95\% CI, 1.43 to $14.90 ; \mathrm{p}<0.05)$. Therefore, in this study, the oral cavity of HIV-infected individuals with a low CD4 count was approximately 5 times more likely to be colonized by Candida spp., implying that the environment in the oral cavity of these patients was likely 5 times more immunosuppressive. Therefore, Candida colonization could be considered as a proxy marker of immunosuppression based on the findings of this study, with potential for use in circumstances where it is not possible to measure CD4 counts. Our results are consistent with those of other studies in this respect [32,34-38]. According to the observations of this study, shared injections increased the risk of Candida colonization in HIV patients by approximately 7-fold compared to other HIV patients (OR, 6.96; 95\% CI, 2.46 to 19.65; $\mathrm{p}<0.001$ ), which aligns with the findings of other studies $[32,39,40]$. Furthermore, the colonization rate of males was approximately 4 times higher than that of females (OR, 3.59; 95\% CI, 1.23 to 10.46; $\mathrm{p}<0.05$ ), which may reflect the higher prevalence of HIV in males [41,42]. Other conditions that may occur, depending on the status of the patient's immune system, include opportunistic infections such as TB. An analysis using the chi-square test showed a significant relationship between TB and oral Candida colonization $(\mathrm{p}<0.05)$. Consistent with other studies [43], oral candidiasis can be a useful clinical tool for screening HIV patients for TB, and we recommend that when an HIV patient with oral candidiasis is referred to a clinic, he or she should be checked for TB and receive prophylaxis for TB [44]. Viral load is another host-related factor, but despite experiments indicating that HIV load reduces immunity on mucosal surfaces and increases the secretion of acid protease from $C$. albicans, the Mann-Whitney test showed that our results were not statistically significant; this finding is in agreement with some studies, but not with others $[10,45,46]$. A possible explanation for this phenomenon might be that insufficient information was available about patients' viral load and that the test was performed among existing patients; therefore, the insufficient data in this study might not have had sufficient statistical power to show these differences.

Our results showed the rate of Candida colonization and Candida spp. abundance and diversity in HIV-infected patients in Ahvaz, Iran. C. albicans was dominant on the oral mucosal surfaces of these patients, and C. dubliniensis was the most common yeast among non-albicans Candida spp. A CD4 count of $\leq 200 / \mathrm{mm}^{3}$ had a strong association with Candida colonization, confirming that the cellular immune response plays a vital role in protecting against OPC and that an impaired immune response could be a 
risk factor. A number of factors, such as viral load and opportunistic infections, require further investigation in larger populations of patients. Therefore, there is a need for further research on this issue in Iran to better clarify these findings.

\section{CONFLICT OF INTEREST}

The authors have no conflicts of interest to declare for this study.

\section{FUNDING}

This study was supported by Ahvaz Jundishapur University of Medical Sciences, Ahvaz, Iran (No. OG-9743).

\section{ACKNOWLEDGEMENTS}

We would like to thank the Infectious and Tropical Diseases Research Center, Health Research Institute, Ahvaz Jundishapur University of Medical Sciences for their support.

\section{AUTHOR CONTRIBUTIONS}

Conceptualization: MF. Data curation: EA, MH. Formal analysis: EA. Funding acquisition: MF. Methodology: EA, MTB, MF. Project administration: MF. Writing - original draft: EA. Writing - review \& editing: $\mathrm{MTB}, \mathrm{MF}, \mathrm{MH}$.

\section{ORCID}

Elham Aboualigalehdari: http://orcid.org/0000-0002-2517-8847; Maryam Tahmasebi Birgani: http://orcid.org/0000-0002-9624-1903; Mahnaz Fatahinia: http://orcid.org/0000-0001-6898-1309; Mehran Hosseinzadeh: http://orcid.org/0000-0002-9761-3713

\section{REFERENCES}

1. Dupont B, Graybill JR, Armstrong D, Laroche R, Touze JE, Wheat LJ. Fungal infections in AIDS patients. J Med Vet Mycol 1992; 30(Suppl 1):19-28.

2. Thompson GR 3rd, Patel PK, Kirkpatrick WR, Westbrook SD, Berg D, Erlandsen J, et al. Oropharyngeal candidiasis in the era of antiretroviral therapy. Oral Surg Oral Med Oral Pathol Oral Radiol Endod 2010;109:488-495.

3. Goulart LS, Souza WW, Vieira CA, Lima JS, Olinda RA, Araújo C. Oral colonization by Candida species in HIV-positive patients: association and antifungal susceptibility study. Einstein (Sao Paulo) 2018;16:eAO4224.

4. Patil S, Rao RS, Majumdar B, Anil S. Clinical appearance of oral candida infection and therapeutic strategies. Front Microbiol 2015; 6:1391.

5. Sardi JC, Scorzoni L, Bernardi T, Fusco-Almeida AM, Mendes Giannini MJ. Candida species: current epidemiology, pathogenicity, biofilm formation, natural antifungal products and new ther- apeutic options. J Med Microbiol 2013;62:10-24.

6. Silva GA, Bernardi TL, Schaker PD, Menegotto M, Valente P. Rapid yeast DNA extraction by boiling and freeze-thawing without using chemical reagents and DNA purification. Braz Arch Biol Technol 2012;55:319-327.

7. Cassone A, Cauda R. Candida and candidiasis in HIV-infected patients: where commensalism, opportunistic behavior and frank pathogenicity lose their borders. AIDS 2012;26:1457-1472.

8. Moris DV, Melhem MS, Martins MA, Mendes RP. Oral Candida spp. colonization in human immunodeficiency virus-infected individuals. J Venom Anim Toxins Incl Trop Dis 2008;14:224-257.

9. Mushi MF, Mtemisika CI, Bader O, Bii C, Mirambo MM, Groß U, et al. High oral carriage of non-albicans Candida spp. among HIVinfected individuals. Int J Infect Dis 2016;49:185-188.

10. Erköse G, Erturan Z. Oral Candida colonization of human immunodeficiency virus infected subjects in Turkey and its relation with viral load and CD4+ T-lymphocyte count. Mycoses 2007; 50:485-490.

11. Yamada $Y$, Makimura K, Merhendi H, Ueda K, Nishiyama $Y$, Yamaguchi $\mathrm{H}$, et al. Comparison of different methods for extraction of mitochondrial DNA from human pathogenic yeasts. Jpn J Infect Dis 2002;55:122-125.

12. Mirhendi H, Makimura K, Khoramizadeh M, Yamaguchi H. A one-enzyme PCR-RFLP assay for identification of six medically important Candida species. Nihon Ishinkin Gakkai Zasshi 2006; 47:225-229.

13. Kianipour S, Ardestani ME, Dehghan P. Identification of Candida albicans and Candida dubliniensis species Isolated from bronchoalveolar lavage samples using genotypic and phenotypic methods. Adv Biomed Res 2018;7:66.

14. Anwar KP, Malik A, Subhan KH. Profile of candidiasis in HIV infected patients. Iran J Microbiol 2012;4:204-209.

15. Nanteza M, Tusiime JB, Kalyango J, Kasangaki A. Association between oral candidiasis and low CD4+ count among HIV positive patients in Hoima Regional Referral Hospital. BMC Oral Health 2014;14:143.

16. Li YY, Chen WY, Li X, Li HB, Li HQ, Wang L, et al. Asymptomatic oral yeast carriage and antifungal susceptibility profile of HIVinfected patients in Kunming, Yunnan Province of China. BMC Infect Dis 2013;13:46.

17. Mushi MF, Bader O, Taverne-Ghadwal L, Bii C, Groß U, Mshana SE. Oral candidiasis among African human immunodeficiency virus-infected individuals: 10 years of systematic review and meta-analysis from sub-Saharan Africa. J Oral Microbiol 2017;9: 1317579.

18. Patil S, Majumdar B, Sarode SC, Sarode GS, Awan KH. Oropharyngeal candidosis in HIV-infected patients-an update. Front Microbiol 2018;9:980.

19. Katiraee F, Teifoori F, Soltani M. Emergence of azole-resistant Candida species in AIDS patients with oropharyngeal candidiasis in Iran. Curr Med Mycol 2015;1:11-16.

20. Kwamin F, Nartey NO, Codjoe FS, Newman MJ. Distribution of Candida species among HIV-positive patients with oropharyn- 
geal candidiasis in Accra, Ghana. J Infect Dev Ctries 2013;7:4145.

21. Menezes Rde P, Borges AS, Araujo LB, Pedroso Rdos S, Röder DV. Related factors for colonization by Candida species in the oral cavity of HIV-infected individuals. Rev Inst Med Trop Sao Paulo 2015;57:413-419.

22. Nadagir SD, Chunchanur SK, Halesh LH, Yasmeen K, Chandrasekhar MR, Patil BS. Significance of isolation and drug susceptibility testing of non-Candida albicans species causing oropharyngeal candidiasis in HIV patients. Southeast Asian J Trop Med Public Health 2008;39:492-495.

23. Das PP, Saikia L, Nath R, Phukan SK. Species distribution \& antifungal susceptibility pattern of oropharyngeal Candida isolates from human immunodeficiency virus infected individuals. Indian J Med Res 2016;143:495-501.

24. Owotade FJ, Patel M. Virulence of oral Candida isolated from HIV-positive women with oral candidiasis and asymptomatic carriers. Oral Surg Oral Med Oral Pathol Oral Radiol 2014;118: 455-460.

25. Patel PK, Erlandsen JE, Kirkpatrick WR, Berg DK, Westbrook $\mathrm{SD}$, Louden C, et al. The changing epidemiology of oropharyngeal candidiasis in patients with HIV/AIDS in the era of antiretroviral therapy. AIDS Res Treat 2012;2012:262471.

26. Sharifzadeh A, Khosravi AR, Shokri H, Sharafi G. Antifungal effect of Trachyspermum ammi against susceptible and fluconazoleresistant strains of Candida albicans. J Mycol Med 2015;25:143150.

27. Khan Z, Ahmad S, Joseph L, Chandy R. Candida dubliniensis: an appraisal of its clinical significance as a bloodstream pathogen. PLoS One 2012;7:e32952.

28. Thanyasrisung P, Kesakomol P, Pipattanagovit P, Youngnak-Piboonratanakit P, Pitiphat W, Matangkasombut O. Oral Candida carriage and immune status in Thai human immunodeficiency virus-infected individuals. J Med Microbiol 2014;63:753-759.

29. Panel on Opportunistic Infections in Adults and Adolescents with HIV. Guidelines for the prevention and treatment of opportunistic infections in adults and adolescents with HIV: recommendations from the Centers for Disease Control and Prevention, the National Institutes of Health, and the HIV Medicine Association of the Infectious Diseases Society of America; 2020 [cited 2020 Jun 15]. Available from: https://aidsinfo.nih.gov/guidelines.

30. Perea S, López-Ribot JL, Wickes BL, Kirkpatrick WR, Dib OP, Bachmann SP, et al. Molecular mechanisms of fluconazole resistance in Candida dubliniensis isolates from human immunodeficiency virus-infected patients with oropharyngeal candidiasis. Antimicrob Agents Chemother 2002;46:1695-1703.

31. Quindós G, Carrillo-Muñoz AJ, Arévalo MP, Salgado J, AlonsoVargas R, Rodrigo JM, et al. In vitro susceptibility of Candida dubliniensis to current and new antifungal agents. Chemotherapy 2000;46:395-401.

32. Wu CJ, Lee HC, Yang YL, Chang CM, Chen HT, Lin CC, et al. Oropharyngeal yeast colonization in HIV-infected outpatients in southern Taiwan: CD4 count, efavirenz therapy and intravenous drug use matter. Clin Microbiol Infect 2012;18:485-490.

33. Manikandan C, Amsath A. Isolation and rapid identification of Candida species from the oral cavity. Int J Pure App Biosci 2013; 1:23-27.

34. Bodhade AS, Ganvir SM, Hazarey VK. Oral manifestations of HIV infection and their correlation with CD4 count. J Oral Sci 2011;53:203-211.

35. Campo J, Del Romero J, Castilla J, García S, Rodríguez C, Bascones A. Oral candidiasis as a clinical marker related to viral load, CD4 lymphocyte count and CD4 lymphocyte percentage in HIVinfected patients. J Oral Pathol Med 2002;31:5-10.

36. Hung CC, Yang YL, Lauderdale TL, McDonald LC, Hsiao CF, Cheng $\mathrm{HH}$, et al. Colonization of human immunodeficiency virus-infected outpatients in Taiwan with Candida species. J Clin Microbiol 2005;43:1600-1603.

37. Imam N, Carpenter CC, Mayer KH, Fisher A, Stein M, Danforth SB. Hierarchical pattern of mucosal candida infections in HIVseropositive women. Am J Med 1990;89:142-146.

38. McCarthy GM, Mackie ID, Koval J, Sandhu HS, Daley TD. Factors associated with increased frequency of HIV-related oral candidiasis. J Oral Pathol Med 1991;20:332-336.

39. Ceballos Salobreña A, Gaitán Cepeda LA, Ruesga MT, Ceballos García L, Quindós G. Prevalence of oral lesions by Candida sp.: their varieties and serotypes in a population of patients with AIDS under a highly active antiretroviral therapy. Rev Iberoam Micol 1998;15:141-145 (Spanish).

40. Katiraee F, Khosravi AR, Khalaj V, Hajiabdolbaghi M, Khaksar A, Rasoolinejad M, et al. Oropharyngeal candidiasis and oral yeast colonization in Iranian human immunodeficiency virus positive patients. J Mycol Med 2010;20:8-14.

41. Joulaei H, Lankarani KB, Kazerooni PA, Marzban M. Number of HIV-infected cases in Iran: true or just an iceberg. Indian J Sex Transm Dis AIDS 2017;38:157-162.

42. Putranti A, Asmarawati TP, Rachman BE, Hadi U. Oral candidiasis as clinical manifestation of HIV/AIDS infection in Airlangga University hospital patients. IOP Conf Ser Earth Environ Sci 2018; 125:012063.

43. Owotade FJ, Patel M, Ralephenya TR, Vergotine G. Oral Candida colonization in HIV-positive women: associated factors and changes following antiretroviral therapy. J Med Microbiol 2013;62:126132.

44. Shiboski CH, Chen H, Ghannoum MA, Komarow L, Evans S, Mukherjee PK, et al. Role of oral candidiasis in TB and HIV coinfection: AIDS Clinical Trial Group Protocol A5253. Int J Tuberc Lung Dis 2014;18:682-688.

45. Campisi G, Pizzo G, Milici ME, Mancuso S, Margiotta V. Candidal carriage in the oral cavity of human immunodeficiency virus-infected subjects. Oral Surg Oral Med Oral Pathol Oral Radiol Endod 2002;93:281-286.

46. Gottfredsson M, Cox GM, Indridason OS, de Almeida GM, Heald AE, Perfect JR. Association of plasma levels of human immunodeficiency virus type 1 RNA and oropharyngeal Candida colonization. J Infect Dis 1999;180:534-537. 